\title{
DIRECT METHANE CONVERSION TO METHANOL
}

Project Status Report - Quarterly

$$
(10 / 01 / 92-12 / 31 / 92)
$$

\author{
Richard D. Noble and John L. Falconer \\ Department of Chemical Engineering \\ University of Colorado \\ Boulder, CO 80309-0424
}

DE93 013998

Prepared for

U.S. Department of Energy

Morgantown Energy Technology Center

Contract No. DE-FG21_90MC27115

\section{DISCLAIMER}

This report was prepared as an account of work sponsored by the United States Government. Neither the United States nor the United States DOE, nor any of their employees, nor any of their contractors, subcontractors, or their employees makes any warranty, express or implied, or assumes any legal liability' or reponsibility for the accuracy, completeness, or usefulness of any information, apparatus, product or process disclosed, or represents that its use would not infringe privately owned rights. 


\title{
DIRECT CATALYTIC CONVERSION OF $\mathrm{CH}_{4}$ TO $\mathrm{CH}_{3} \mathrm{OH}$ IN A NGN-ISOTHERMAL MEMBRANE REACTOR
}

\author{
PROJECT STATUS REPORT -- QUARTERLY
}

$(10 / 01 / 92--12 / 31 / 92)$

\begin{abstract}
PROJECT DESCRIPTION
We proposed to demonstrate the effectiveness of a catalytic membrane reactor (a ceramic membrane combined with a catalyst) to selectively produce methanol by partial oxidation of methane. Methanol is used as a chemical feedstock, gasoline additive, and turbine fuel. Methane partial oxidation using a catalytic membrane reactor has been determined as one of the promising approaches for methanol synthesis from methane. In the original proposal, the membrane was used to be used to selectively remove methanol from the reaction zone before carbon oxides form, thus increasing the methanol yield. Methanol synthesis and separation in one step would also make methane more valuable for producing chemicals and fuels.
\end{abstract}

\section{CURRENT SITUATION}

The cooling tube inserted inside the membrane reactor has created a low temperature zone that rapidly quenches the product stream. This system has proved effective for increasing methanol selectivity during $\mathrm{CH}_{4}$ oxidation, and we are using and modifying this non-isothermal, non-permselective membrane reactor.

\section{PROGRESS}

Experiments were performed in this quarter, using both the original cooling tube $(1 / 4$ inch stainless steel tube) and one with a smaller diameter (5/32 inch, also stainless steel). when the smaller cooling tube was used, selectivity to methanol was not as high as for the $1 / 4$ inch tube. The highest methanol selectivities obtained were $26 \%$ to $28 \%$ with the smaller tube whereas in our previous experiments with a $1 / 4$ inch tube, selectivities of $25 \%$ to $40 \%$ were obtained. These 
results demonstrate that the change in the reactor radial temperature profile had a large effect on methanol selectivity. The smaller tube resulted in a number of changes in the reactor properties. The temperature gradient changed and the membrane temperature was thus different. The distance that molecules traveled before contacting the cooling surface increased and also the volume between the cooling tube and the membrane increased a factor of 4 . This affected the resident time in this region also.

Shorter membranes were also used in the system, for both the original and the smaller cooling tube. The highest selectivity for methanol was about $30 \%$ at a $\mathrm{CH}_{4}$ conversion of $5.5 \%$. This is slightly lower than in our previous experiments. A higher temperature was needed for a given $\mathrm{CH}_{4}$ conversion (for the smaller cooling tube) compared to the previous experiments, apparently because of the shorter contact time with the catalyst.

When the system was changed back to the earlier configuration, with both a long membrane tube and a $1 / 4$ inch cooling tube, the selectivities were the same as obtained in earlier experiments. Because of number of other improvements in the system to avoid hold up of liquids in the reactor, a stable methanol selectivity of $32 \%$ was obtained. In the previous experiments, the selectivities varied from $25 \%$ to $40 \%$.

Additional modification to the reactor also all owed the temperatures of the catalyst bed and the exiting cooling water to be measured. The temperature of the catalyst bed is sensitive to the cooling tube temperature, and the catalyst bed is in a low temperature zone. While the temperature of exiting water of the cooling tube is about $16^{\circ} \mathrm{C}$, the highest temperature measured for catalyst bed is about $200^{\circ} \mathrm{C}$. This temperature does not seem to be high enough for to catalyze reaction, but other experiments have indicated the catalyst makes a difference. We are planning experiments that will clarify the role of the catalyst when cooling is used.

Use of the original cooling tube (1/4 inch) caused the membranes to break, as reported previously. When membranes were broken inside the reactor, both lower selectivity for methanol and conversion of methane were obtained. An optimal cooling tube size should avoid this 
problem.

A poster on this work was presented at the Annual AIChE meeting in Miami Beach in November, 1992.

\section{WORK PLANNED FOR CURRENT QUARTER}

1. Clarify the role of the catalyst bed in this process. A metering valve will be installed so the flow rate of cooling water can be adjusted and thus the catalyst temperature can be adjusted. A replacement of the catalyst with blank supporting material (silica gel) will also be performed.

2. Clarify the role of the membrane in this process. Replace the Alcoa membrane with other membranes (different material, different pore size).

3. Systematic studies to determine optimal operating conditions (temperature, pressure, resident time and oxygen concentration).

These tasks are continuing and will not be completed in the current quarter. 

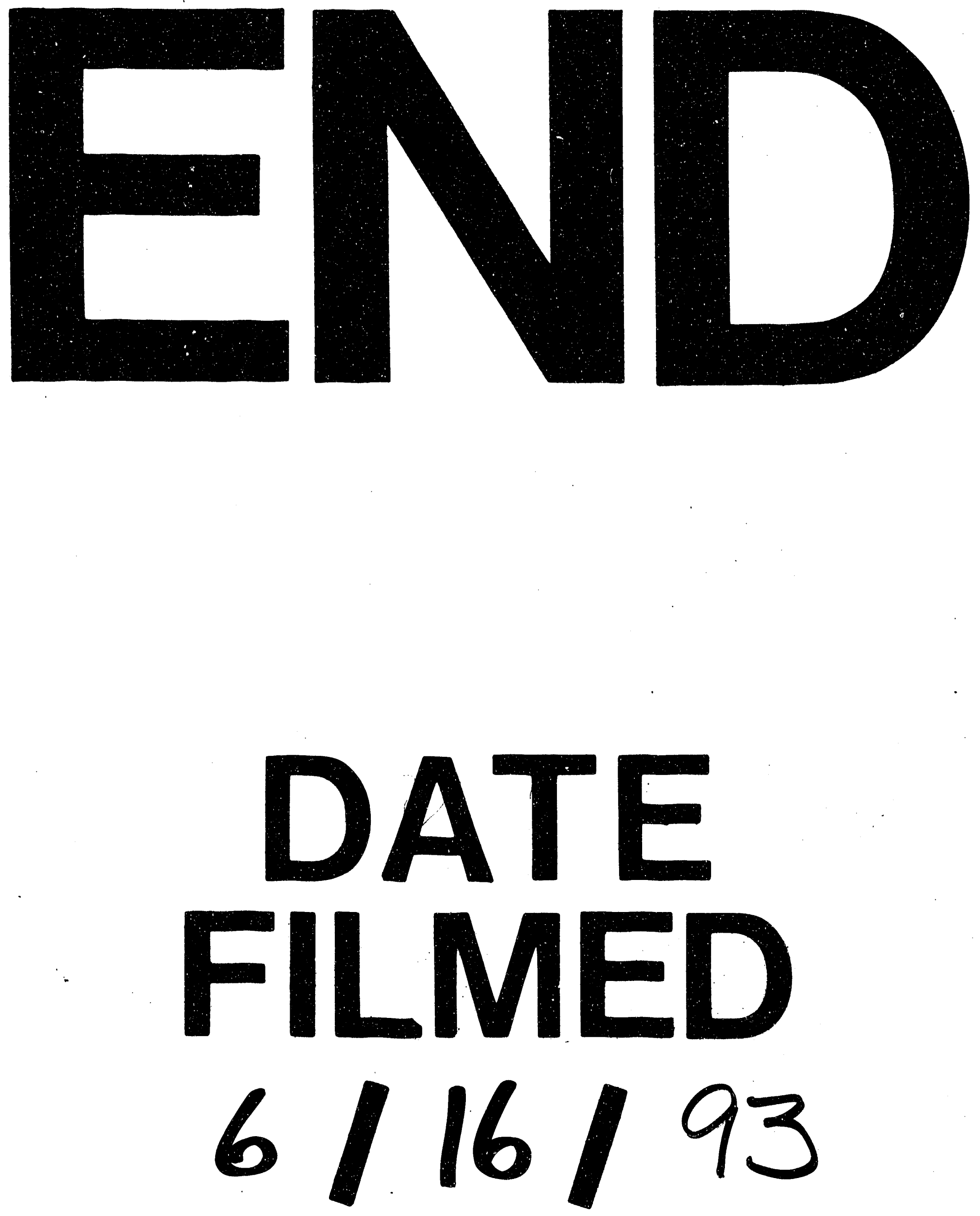
